\title{
Metastatic melanoma of unknown primary in the temporalis muscle
}

\author{
Marco Dalle Carbonare, ${ }^{1}$ Mei Xien Goh, ${ }^{1}$ Zainab AlshiekhAli, ${ }^{2}$ David Howlett ${ }^{3}$
}

${ }^{1}$ Oral and Maxillofacial Surgery Department, Eastbourne District General Hospital, Eastbourne, UK

${ }^{2}$ Pathology Department, Eastbourne District General Hospital, Eastbourne, UK ${ }^{3}$ Radiology Department, Eastbourne District General Hospital, Eastbourne, UK

\section{Correspondence to}

Dr Marco Dalle Carbonare, marcodallecarbonare@hotmail.it

Accepted 7 October 2017

\section{SUMMARY}

Melanomas are aggressive cancers that present as cutaneous, mucosal and ocular lesions with the ability to metastasise widely. There are, however, occasions where lesions are found in distant sites such as lymph nodes, viscera and subcutaneous tissues without clinically apparent skin involvement. This is known as metastatic melanoma of unknown primary (MUP). Its presentation in skeletal muscle is rare, and the available literature is sparse. This article presents an 85-year-old woman with a MUP presenting in the right temporalis muscle, which was diagnosed with the aid of the ultrasound-guided core biopsy. The melanoma deposit was successfully excised, and no recurrence was identified. The patient is now under close follow-up.

\section{BACKGROUND}

Melanomas are typically pigmented lesions that increase in size, some with crusting, bleeding and ulceration. The site of their presentation allows for classification-cutaneous, mucosal, ocular or metastatic. Known for their aggressive nature, melanomas are capable of metastasising widely. Generally, metastases tend to present in distant subcutaneous sites, lymph nodes, visceral organs and very rarely skeletal muscle unless by way of direct spread. Most

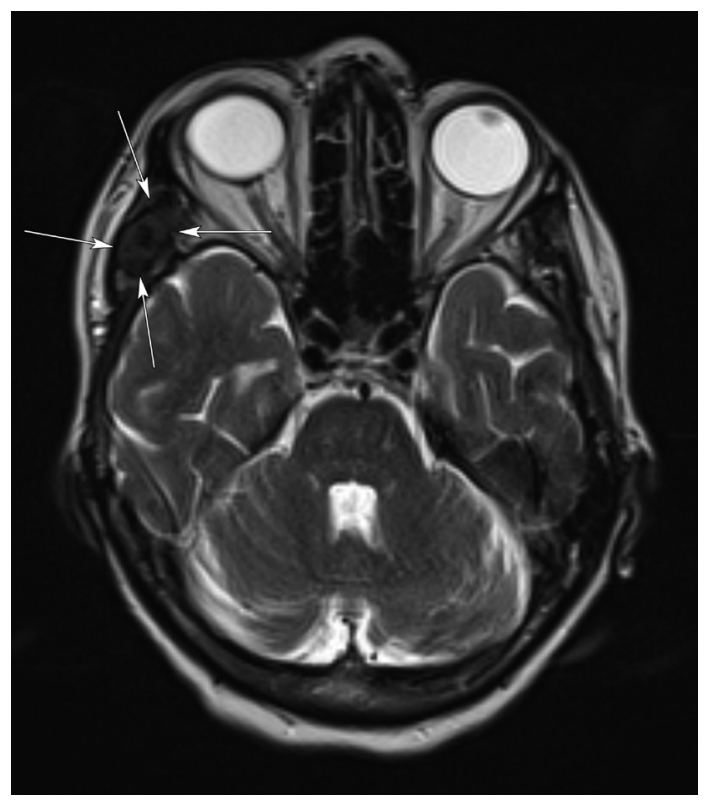

Figure 1 Axial T2W MRI at the level of the temporalis muscles shows a lobulated mass in the right temporalis. This is of diffusely low signal. melanomas have a known primary, over 90\% of which have a cutaneous origin. ${ }^{1}$ There are, however, documented cases where secondary deposits present, mimicking metastasis in the absence of a primary tumour. This is known as a melanoma of unknown primary (MUP). It is defined as 'the presence of a histologically confirmed melanoma in a lymph node, skin/subcutaneous or visceral tissues without any evidence of a primary lesion'. ${ }^{2}$ Ranging between $1.4 \%$ and $5.6 \%$ of all melanomas, ${ }^{1-3}$ MUPs are known to occur with approximately $60 \%$ presenting in lymph nodes. ${ }^{4}$ Reports of intramuscular lesions are sparse, more so when localised to the temporalis muscle. This article presents a rare case of melanoma in the temporalis muscle with no known primary.

\section{CASE PRESENTATION}

An 85-year-old woman presented a tender rightsided mass on her temporal region to the Head \& Neck clinic in October 2016. This had been present for several weeks and was slowly enlarging, causing restriction to mouth opening. She was otherwise well, and her medical history was unremarkable.

On examination, the mass was soft and fixed and was situated in the right temporal fossa. She was found to have significant trismus. Clinical examination was otherwise normal, in particular, there was no palpable cervical lymphadenopathy.

\section{INVESTIGATIONS}

Initially, the possibility of a dermoid/epidermoid cyst, metastases and a sarcomatous lesion was considered, and the patient was referred for MR assessment (figures 1 and 2). MRI demonstrated a $22 \mathrm{~mm} \times 12 \mathrm{~mm} \times 18 \mathrm{~mm}$ heterogeneous high $\mathrm{T} 1$ signal and low T2 signal mass in the right temporalis muscle. The lesion was markedly hypodense on T2W, high signal on T1W-there was no suppression on Short-TI Inversion Recovery (STIR) suggesting no significant fat content, also no evidence of haemorrhage on gradient echo imaging. There was some peripheral enhancement post-gadolinium administration. These MR features are highly suggestive of a melanin-containing lesion with the paramagnetic effects of melanin shortening T2W relaxation times. The higher the concentration of melanin, the more profound the signal changes.

Histopathological sampling was undertaken to confirm the diagnosis, but initial fine-needle aspiration biopsy was inconclusive. 


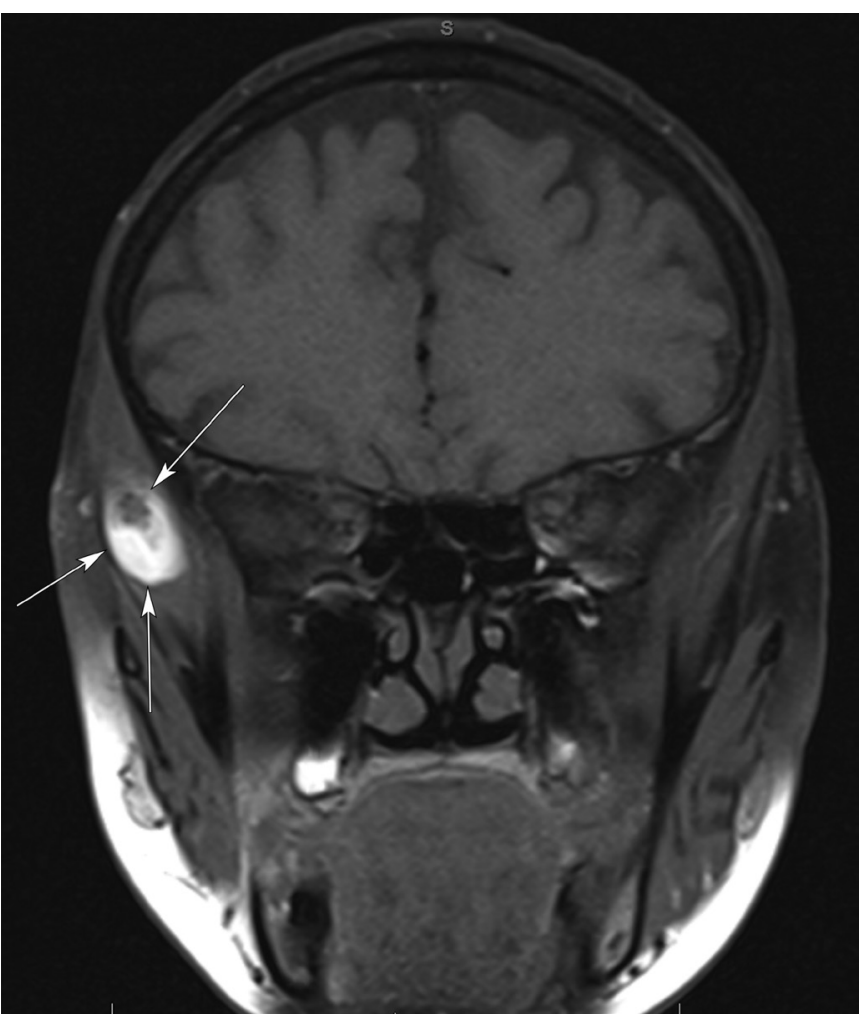

Figure 2 Coronal T1W fat saturated image through temporalis region. This confirms right temporalis muscle mass, and this is of high signal with no fat saturation. This very high signal on T1W combined with low signal on $\mathrm{T} 2 \mathrm{~W}$ is highly suggestive of high melanin content within a melanoma deposit. There was minor peripheral enhancement following intravenous gadolinium administration.

An ultrasound-guided core biopsy (USCB) was then performed (with an $18 \mathrm{G}$ needle), which showed the presence of spindle and epithelioid cells containing brown pigments. Atypical nucleoli positive to HMB45 and melan-A were also individualised. Further genetic testing detected mutations in the BRAF codon 600 (exon 15). These findings were consistent with that of a malignant melanoma (figure 3). A CT scan with contrast of the

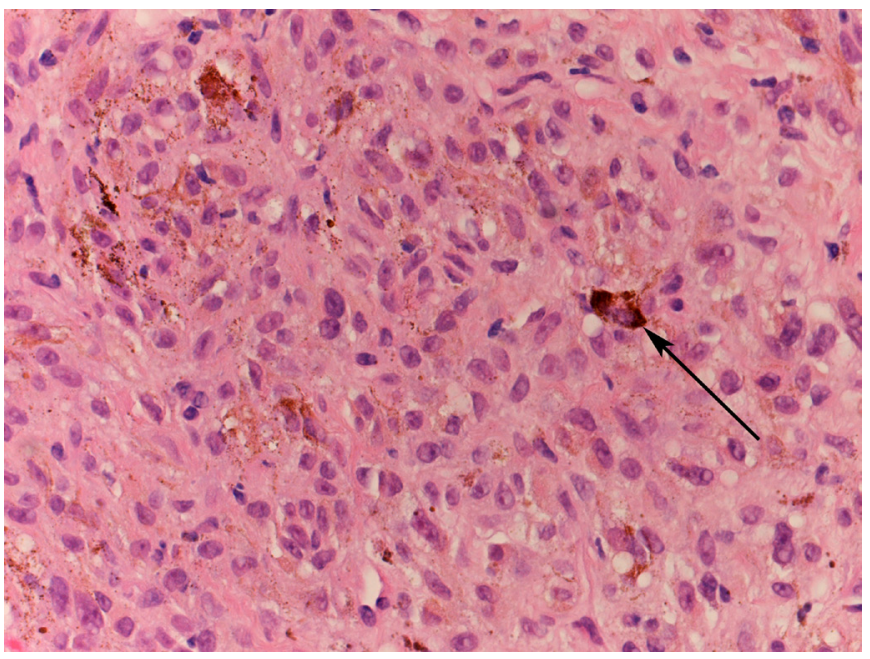

Figure 3 Histology of core biopsy specimen undertaken (H\&E stain, $\times 40$ magnification) notes tumour cells containing extensive melanin pigment (arrow).

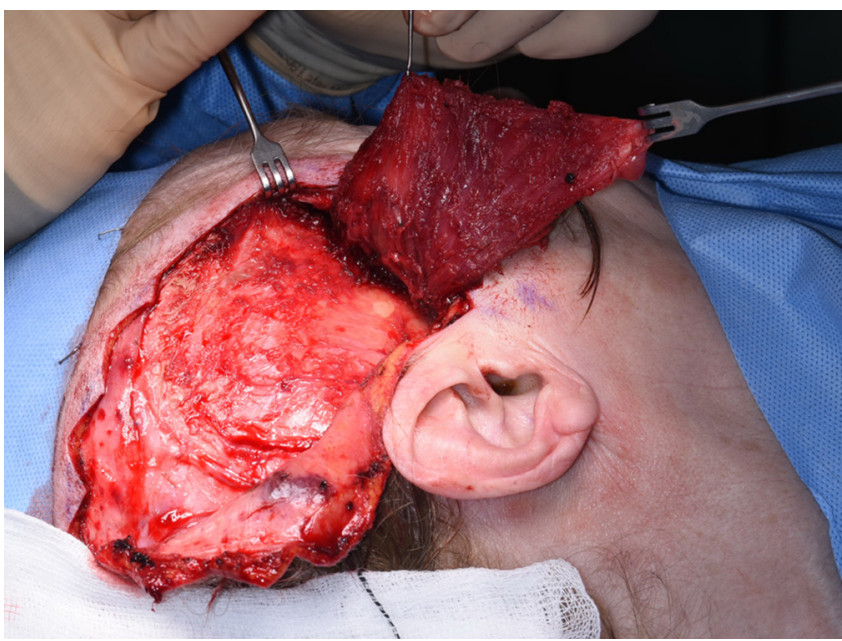

Figure 4 Wide local excision of the melanoma deposit. Narrow but satisfactory margins $(0.5 \mathrm{~mm}$ deep margin) were obtained. No neck dissection was performed.

brain/neck/chest/abdomen/pelvis revealed no evidence of metastatic disease.

The patient then also underwent extensive ophthalmological, cutaneous and anogenital examinations, and no primary lesion was found.

\section{OUTCOME AND FOLLOW-UP}

Diagnosed with an MUP presenting in the right temporalis, the woman was referred for surgical wide excision of the primary temporalis lesion, which was undertaken in February 2017 (figure 4). Three months after the surgical procedure, the patient underwent another MRI scan; no evidence of recurrence nor presence of new metastases was identified. She is now under close clinical follow-up.

\section{DISCUSSION}

Das Gupta et al first published in $1963^{5}$ a study where they outlined specific exclusion criteria for the diagnosis of true MUPs, which have been widely adopted in the literature-as was done in this case.

Patient with presumed MUPs needs to comply with the following criteria:

A. Absence of previous metastatic melanoma with evidence of orbital enucleation or exenteration;

B. Absence of any excision/cauterisation of a mole, freckle, birthmark or other skin lesion, where the diagnosis of melanoma might have been missed;

C. Absence of scar after previous local treatment in the skin drained by the involved lymphatic base;

D. Failure to identify a primary melanoma after a thorough skin, mucosal (nasal, oral and anogenital) and ophthalmological examination.

MUPs are confirmed after that a detailed standardised evaluation ${ }^{5}$ fails to identify the primary site. Although there is no consensus on how much diagnostic investigations are needed before MUP is confirmed, a multidisciplinary approach involving surgeon, oncologist, radiologist, pathologist and dermatologist (to help evaluate the presence of a potential primary melanoma) is recommended, including in this process comprehensive imaging of the whole body to exclude metastatic disease. ${ }^{6}$ Such approach has been emphasised in recent guidelines of management of all cancers of unknown primary sites. ${ }^{7}$ 
The pathogenesis of MUPs is still not fully understood. Three main theories have been suggested across the literature: the complete and spontaneous regression of an unrecognised primary melanoma, the excision of a histologically misdiagnosed melanoma or the malignant transformation of an ectopic melanocyte in lymph nodes, viscera or site of lesion. ${ }^{124}$

As mentioned, the presentation of melanomas as an intramuscular lesion is rare. To our knowledge, only two published cases have reported the presence of a melanoma in the temporalis muscle. One was due to the metastasis from the ciliary body of the eye, ${ }^{8}$ whereas the other was similar to our case. ${ }^{9}$ In the second one, ${ }^{9}$ the patient was similarly asymptomatic, aside from the lump, and MRI had failed to demonstrate the lesion. The diagnosis of melanoma was only obtained after surgical excision during which two separate deposits were noted in the muscle.

In our case, the lesion was clearly delineated with MR. It also demonstrated MR features associated with the paramagnetic effects of melanin - rarely on low signal T2 weighting, moderately high signal on T1 weighting and no evidence of fat suppression. ${ }^{10} 11$

Following initial inconclusive fine-needle aspiration cytology (FNAC), the USCB was undertaken, and it confirmed the diagnosis. There is increasing evidence within the literature of the improved diagnostic yield of USCB over FNAC, particularly if malignancy is suspected. This in part relates to the provision of a core of tissue which can be sent for immune-histochemical analysis, allowing tumour typing and grading. ${ }^{12} 13$

In staging MUPs, the consensus is that those presenting in lymph nodes or distant skin/subcutaneous tissues are classed as stage III melanomas and all others, stage IV. ${ }^{1}$ In their study, Anbari et al ${ }^{4}$ identified lymph node involvement in 65\% (26/40) of MUPs. The most frequent sites of lymph node involvement were the axilla (14/26\%-54\%), the neck (7/26\%-27\%) and the groin (5/26\%-19\%). Visceral and subcutaneous metastatic involvement accounted for $11(28 \%)$ and $3(8 \%)$, respectively.

Bae et $a l^{2}$ observed that an increased stage and older age were the main risk factors in the survival of patients with MUP with no lymph node involvement, whereas the number of affected lymph nodes was the most important factor in patients presenting stage III MUP. That said, when comparing survival rates of patients with MUPs to those with known primaries (MKPs), it was observed ${ }^{124}$ that following treatment, patients with MUPs (regardless of lymphatic involvement) fared better than those with MKPs. The 4-year survival rate in patients with MKPs ranges from $13 \%$ to $19 \%,{ }^{14}$ whereas the 4 -year survival rate in patients with MUP is between $45 \%$ and $57 \% .^{24}$

The better prognosis of MUPs is thought to relate to underlying immunological mechanisms, supporting the hypothesis that the primary lesion may undergo spontaneous and complete regression. Treatment for MUPs generally matches that of MKPs, based on the staging of the lesion. It will range from wide surgical excision, neck dissections, chemotherapy and radiotherapy. As very little is known about intramuscular lesions, little can be inferred about the optimum management and prognosis.

Contributors All authors have contributed to the manuscript. MDC and MXG were equally responsible and carried out the acquisition, analysis and interpretation of data, the bibliographic review and the major drafting of the article. ZAA and DH were responsible for the histopathological and radiological aspects of the scientific paper, respectively. They also carried out the final critical revision of the manuscript and approved the final draft. MDC and DH were responsible for the initial conception
Learning points

Melanomas are known to be aggressive cancers that metastasise widely.

- Melanoma of unknown primaries (MUPs) are not rare, accounting for $1.4 \%-5.6 \%$ of all melanomas. Chances of a 4-year survival rate in patients with a diagnosed MUP can be three times higher than in those with a melanoma of known primary.

- More than $60 \%$ of all MUPs can be found in the lymph nodes, being the axilla the area of major involvement.

- Melanoma of unknown primary proves to be a diagnostic challenge. However, the latest technological advancements in imaging and immunohistochemistry, such as the use of $\mathrm{CT}$, MR and positron emission tomography and appropriate tissue sampling (ultrasound-guided core biopsy), alongside a thorough physical examination, have helped the multidisciplinary team identify and facilitate treatment for these lesions.

and design of the current study. The final revisions were done by MDC and MXG and finally approved by ZAA and DH.

Competing interests None declared.

Patient consent Obtained.

Provenance and peer review Not commissioned; externally peer reviewed.

(c) BMJ Publishing Group Ltd (unless otherwise stated in the text of the article) 2017. All rights reserved. No commercial use is permitted unless otherwise expressly granted.

\section{REFERENCES}

1 Kamposioras K, Pentheroudakis G, Pectasides D, et al. Malignant melanoma of unknown primary site. To make the long story short. A systematic review of the literature. Crit Rev Oncol Hematol 2011;78:112-26.

2 Bae JM, Choi YY, Kim DS, et al. Metastatic melanomas of unknown primary show better prognosis than those of known primary: a systematic review and meta-analysis of observational studies. J Am Acad Dermatol 2015;72:59-70.

3 Ribero S, Pampena R, Bataille V, et al. Unknown Primary Melanoma: Worldwide Survey on Clinical Management. Dermatology 2016:232:704-7.

4 Anbari KK, Schuchter LM, Bucky LP, et al. Melanoma of unknown primary site: presentation, treatment, and prognosis - a single institutional study. Cancer 1997:79:1816-21.

5 Das Gupta T, Bowden L, Berg JW. Malignant melanoma of unknown primary origin. Surg Gynecol Obstet 1963;117:341-5.

6 Kim KW, Krajewski KM, Jagannathan JP, et al. Cancer of unknown primary sites: what radiologists need to know and what oncologists want to know. AJR Am J Roentgenol 2013;200:484-92.

7 Ettinger DS, Agulnik M, Cates JM, et al. NCCN Clinical Practice Guidelines Occult primary. J Nat/ Compr Canc Netw 2011;9:1358-95.

8 Oittinen HA, O'Shaughnessy M, Cullinane AB, et al. Malignant melanoma of the ciliary body presenting as extraocular metastasis in the temporalis muscle. J Clin Pathol 2007;60:834-5.

9 Mercer NS, Devaraj VS. Intramuscular metastatic melanoma with an unknown primary. Br J Plast Surg 1990;43:367-8.

10 Gaviani P, Mullins ME, Braga TA, et al. Improved detection of metastatic melanoma by T2*-weighted imaging. AJNR Am J Neuroradiol 2006;27:605-8.

11 Isiklar I, Leeds NE, Fuller GN, et al. Intracranial metastatic melanoma: correlation between MR imaging characteristics and melanin content. AJR Am J Roentgenol 1995; 165:1503-12.

12 Schmidt RL, Hunt JP, Hall BJ, et al. A systematic review and meta-analysis of the diagnostic accuracy of frozen section for parotid gland lesions. Am J Clin Pathol 2011;136:729-38.

13 Schmidt RL, Hall BJ, Wilson AR, et al. A systematic review and meta-analysis of the diagnostic accuracy of ultrasound-guided core needle biopsy for salivary gland lesions. Am J Clin Pathol 2011;136:45-59.

14 Tas F. Metastatic behavior in melanoma: timing, pattern, survival, and influencing factors. J Oncol 2012;2012:1-9. 


\section{Unusual association of diseases/symptoms}

Copyright 2017 BMJ Publishing Group. All rights reserved. For permission to reuse any of this content visit http://group.bmj.com/group/rights-licensing/permissions.

BMJ Case Report Fellows may re-use this article for personal use and teaching without any further permission.

Become a Fellow of BMJ Case Reports today and you can:

- Submit as many cases as you like

- Enjoy fast sympathetic peer review and rapid publication of accepted articles

- Access all the published articles

- Re-use any of the published material for personal use and teaching without further permission

For information on Institutional Fellowships contact consortiasales@bmjgroup.com

Visit casereports.bmj.com for more articles like this and to become a Fellow 